\title{
THE USE OF FREE AUTOGENOUS RIB GRAFTS IN MAXILLOFACIAL RECONSTRUCTION
}

\author{
"P. DONKOR, D.O. BANKAS, G. BOAKYE ${ }^{1}$, S. ANSAH and A.O. ACHEAMPONG \\ Oral and Maxillofacial Unit, Departments of Surgery and ${ }^{1}$ Anaesthesia, Kwame Nkrumah Uni- \\ versity of Science and Technology, School of Medical Sciences, Komfo Anokye Teaching Hospi- \\ tal, Kumasi, Ghana
}

\begin{abstract}
SUMMARY
Background: Hard tissue defects in the maxillofacial region due to trauma or ablative surgery result in functional and cosmetic problems. State-of-theart methods for reconstruction include the use of vascularised tissue.

Objective: To review our results with the use of non-vascularised rib grafts for maxillofacial reconstruction.

Method: Patients who underwent maxillofacial reconstruction using rib at the Komfo Anokye Teaching Hospital during 1996-2004 were studied. The technique for rib harvest and implantation of the graft was standardized. Clindamycin was administered peri-operatively and the harvested rib was temporarily stored in clindamycin/saline before implantation. The graft was successful if it survived beyond 6 months after placement. Follow-up was for at least 12 months postoperatively.

Results: A total of 29 patients were studied. The indications for grafting included ameloblastoma, malignant disease, cyst, ankylosis, and trauma. Either rib bone only or with cartilage were used. In $90 \%$ of patients (26/29) the graft healed uneventfully. Two patients had dehiscence of the wound with exposure of the graft intraorally within two weeks of surgery and were successfully managed with antibiotics.

Conclusion: Free autogenous rib was successfully used to reconstruct defects in the maxillofacial region. Further stabilization of the graft by intermaxillary fixation and the prophylactic use of clindamycin may have helped to minimize complications.
\end{abstract}

Keywords: Rib, non-vascularised graft, maxillofacial reconstruction, mandible.

\section{INTRODUCTION}

Facial disfigurement can result from bone deficiency following trauma or surgery. To minimize the associated functional and cosmetic problems a number of reconstructive options are available to the surgeon including the use of autogenous and alloplastic implants ${ }^{1,2}$. The most common alloplastic implants include titanium bone plates and screws, which though well tolerated are associated with delayed complications including implant extrusion or fracture ${ }^{3}$.

Sources of free non-vascularised bone grafts include calvarium, rib, ilium, tibia, fibula, scapula and radius ${ }^{4}$. Their usefulness have, however, been limited by early bone resorption and infection ${ }^{5}$. Vascularised grafts are now the state-of-the-art for bone replacement in the maxillofacial region ${ }^{6}$, as they are reliable, resistant to radiation and infection, and allow the placement of dental implants. Their disadvantages include high cost, the need for specialized training and equipment as well as significant donor site morbidity ${ }^{7,8}$.

In Ghana, resource constraints combined with lack of requisite skills limit the reconstructive options available to the surgeon. The lack of universal health insurance and widespread poverty among patients also influence the treatment choices they make, and therefore limit access to reconstruction following ablative surgery.

In our practice patients commonly present with advanced facial tumours. Resection of these tumours usually involves large segments of bone. Where possible, reconstruction of the ensuing defect is carried out at the same operation using autogenous non-vascularised tissue. A smaller number of patients with pre-existing traumatic defects of bone and soft tissue also undergo reconstruction. The purpose of this study was to review the outcome of non-vascularised autogenous rib grafts used in some of our patients.

\section{PATIENTS AND METHODS}

Patients with hard tissue defects resulting from trauma or elective surgery treated at the Komfo Anokye Teaching Hospital during the 9-year pe-

\footnotetext{
* Author for correspondence
} 
riod from 1996-2004 form the study sample. Information on sex, age, diagnosis, operative procedure, and outcome was obtained from patient records. The surgical technique of rib harvest, its storage, and subsequent implantation has been standardized in our unit. Grafts harvested were either rib bone, rib bone with cartilage, or cartilage alone. The graft was considered to be successful if healing was uncomplicated within the first 6 months of its placement. Only patients who were followed up for at least 12 months were included in the analysis.

\section{Surgical Technique}

A pre-operative chest x-ray was taken in all cases to rule out pre-existing chest pathology. The size of the $f$ defect to be reconstructed was estimated by comparing with either adjacent structures or the normal side where applicable. Surgery was carried out under general anaesthesia via nastrocheal, orotracheal, fiberoptic intubation or a tracheostomy. Pre-operatively, 300mg clindamycin was administered intravenously. The appropriate length of rib, usually $5^{\text {th }}$ and $6^{\text {th }}$, was harvested through an anterior chest incision with preservation of the periosteal envelope. The bone graft was then stored in a solution of $300 \mathrm{mg}$ clindamycin $/ 500 \mathrm{ml}$ normal saline. Following careful haemostasis the donor site was closed in layers without drainage and a pressure dressing was applied. The site of the facial lesion was then operated upon and prepared to receive the bone graft. The graft was molded to fit the defect and secured with either mini-plates or wires. Intermaxillary fixation was applied for 4 weeks except where the reconstruction was for ankylosis of the mandible, when the fixation was maintained for only 72 hours. The wound at the recipient site was closed in layers after placing a drain. Where the ear was reconstructed a firm pressure dressing was applied for at least one week. Adult patients were prescribed oral clindamycin 500mg t.i.d. for 5 days after the operation, with the dose being appropriately adjusted for younger patients.

\section{RESULTS}

A total of 29 patients made up of 18 males and 11 females were studied. Their ages ranged from 12 to 65 years with a mean of 35.5years. The main indications for grafting were ameloblastoma and ankylosis (Table 1). More than $80 \%$ of the reconstructions involved the mandible. Rib cartilage was used for ear reconstruction in two (2) patients. In the immediate post-operative period all the patients complained of mild donor site pain which was successfully managed with non-steroidal an- algesics. Majority (26/29) of patients had no graftrelated complications. Intra-oral wound dehiscence with exposure of the graft was seen in two patients. In both cases this was successfully managed with antibiotics. In one patient the bone graft underwent early resorption within 6 months of the procedure (Table 2).

Table 1 Indications for grafting

\begin{tabular}{lc} 
Indication & Frequency \\
\hline Ameloblastoma & 10 \\
Ankylosis of TMJ & 6 \\
Post trauma & 5 \\
Osteogenic sarcoma & 2 \\
Ear deformity & 2 \\
Odontogenic keratocyst & 1 \\
Hemifacial microsomia & 2 \\
Post-mandibulectomy deformity & 1 \\
\hline All indications & $\mathbf{2 9}$ \\
\hline
\end{tabular}

Table 2 Complications and outcomes of the grafts

\begin{tabular}{lccl}
\multicolumn{1}{c}{ Complication } & \multicolumn{3}{c}{$\begin{array}{c}\text { Number of patients affected } \\
(\mathbf{n = 2 9 )}\end{array}$} \\
& *Early & ${ }^{+}$Late & Outcome \\
\hline $\begin{array}{l}\text { Wound dehiscence } \\
\text { Resorption of graft }\end{array}$ & 2 & - & Healed \\
$\begin{array}{l}\text { Tumour recurrence } \\
\text { in graft }\end{array}$ & 1 & 1 & Lost \\
Nil & - & 2 & Excised \\
\hline *Early = complication occurring within 6 months after surgery \\
+Late = complication occurring more than 6 months after surgery
\end{tabular}

Late complications included recurrence of tumour in the bone graft in two patients who were operated for osteosarcoma of the mandible, unaesthetic wrinkling of redundant facial skin and hypertrophic scarring (Figure 2b).

In all cases except where the graft underwent resorption, there was an improved appearance and prosthetic rehabilitation was easier. (Figures 1, 2, 3 and 4).

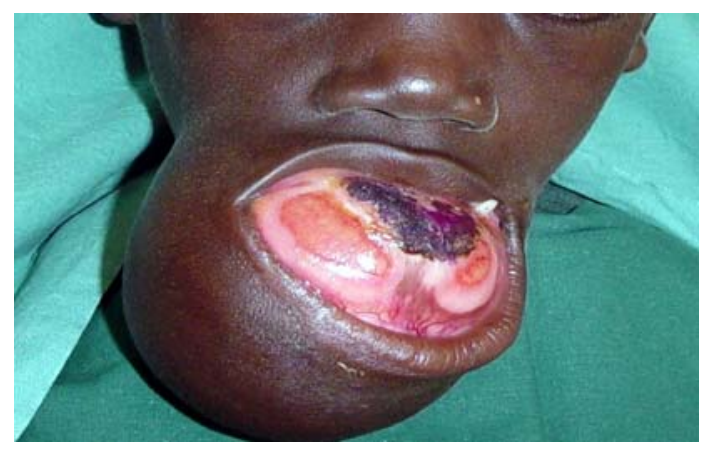

Figure 1a Child with osteosarcoma before surgery 


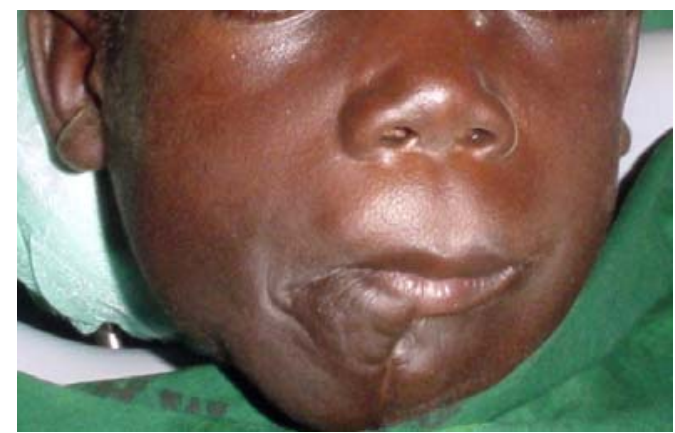

Figure 1b Child with osteosarcoma after surgery

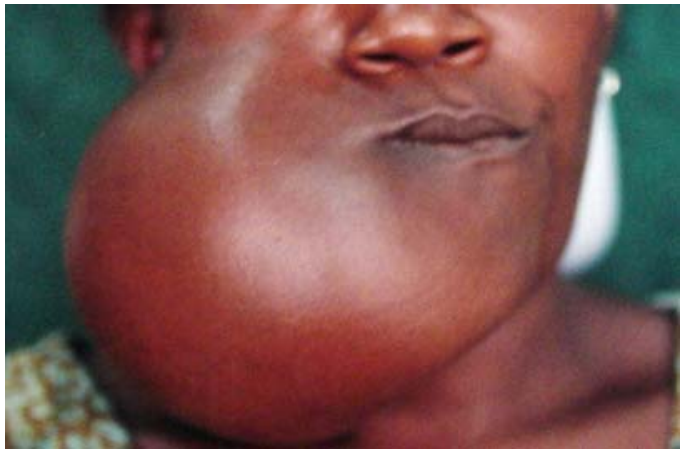

Figure 2a Female with ameloblastoma of mandible before surgery

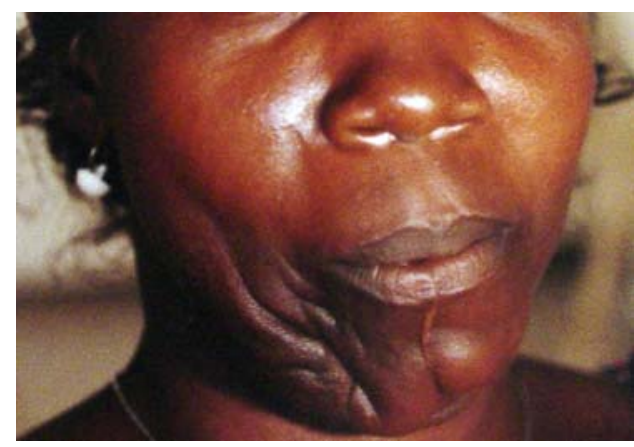

Figure 2b Female in Fig 2a after surgery showing hypertrophic scarring and unaesthetic wrinkling of excess skin

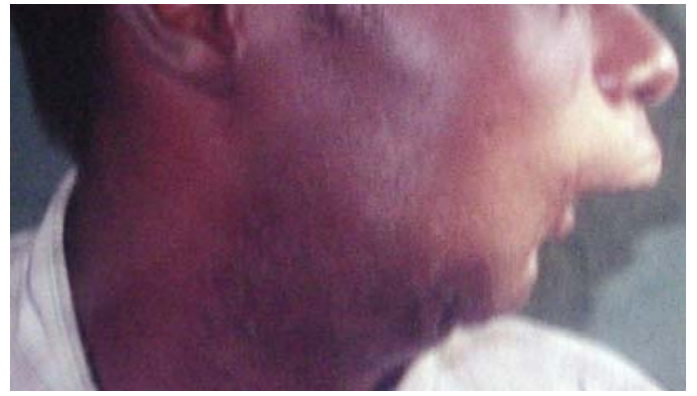

Figure 3a Male with post-surgical deformity of mandible

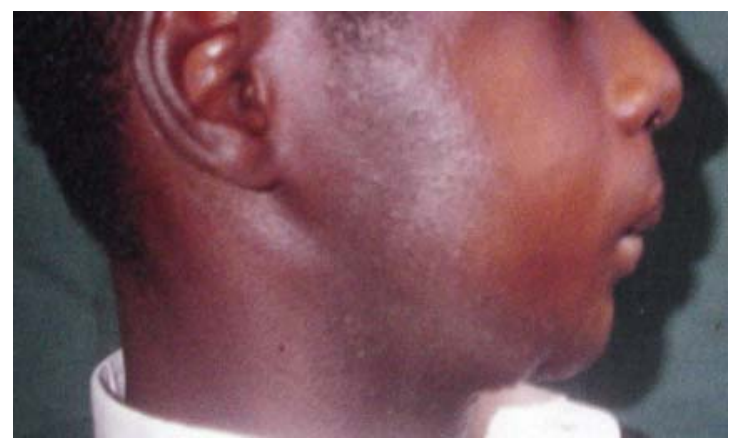

Figure 3b Male with post-surgical deformity after reconstruction

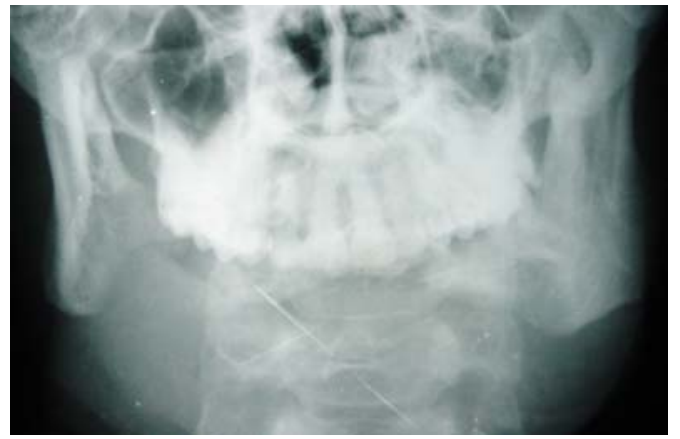

Figure 4a Radiograph showing angle-to-angle defect of mandible

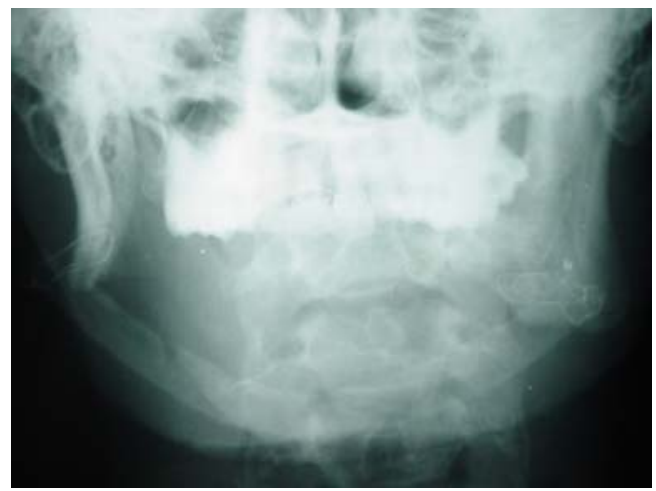

Figure 4b Radiograph showing rib graft in place of previous defect

\section{DISCUSSION}

The sample is small considering the fact that large jaw tumours are common in our part of the world. One possible reason for this was that, in the prevailing fee for service (“cash and carry") system of health financing, not all the patients who had their tumours excised could afford the added cost of immediate reconstruction.

The use of free non-vascularised bone grafts to replace large segments of facial bone has been 
superseded by microvascular techniques in developed countries where such skills and facilities are readily available and outcomes are more predictable $^{7}$. Vascularised grafts are less likely to get infected or resorb as compared with nonvascularised ones. In developing countries, however, the older reconstructive techniques still have a place provided steps are taken to minimize graft failure.

In this series, majority of the grafts survived even when they bridged long defects of jaw bone. One graft failed completely after undergoing early resorption. This was attributed to early loading with a denture. Two grafts dehisced intra-orally but survived after antibiotic therapy. The dehiscence was attributed to excessive tension in the mucosal closure. Salivary contamination resulting in infection of the graft partly accounts for failure of free grafts $^{9}$. The low infection rate observed in this study ${ }^{10}$ could be attributed to the additional stabilization of the grafts by the use of intermaxillary fixation, and the prophylactic use of systemic clindamycin as well as the temporary storage of the graft in a clindamycin-saline solution. Clindamycin is a broad spectrum antibiotic which is active against aerobic, anaerobic, and beta-lactamase producing pathogens. It has significant tissue penetration including bone $\mathrm{b}^{11}$. Its prophylactic use both intra-operatively and post-operatively, ensured that the drug became incorporated into the graft and the surrounding blood clot and was also freely available in the circulation.

Early graft-related complications were few. Tumour recurrence in the graft was a late complication and was seen in two cases. This was thought to be due to inadequate excision of tumour during the initial surgery and could have been avoided if microvascular reconstruction had been available $^{12,13}$.

Apart from post-operative pain which was successfully managed with analgesics no significant morbidity at the donor site was reported, making this procedure relatively safe and attractive to use. Even though the rib grafts offered little bulk in the mandible, they provided an effective skeletal base to support a denture.

The majority of the reconstructions followed surgery for ameloblastoma of the mandible. These tumours are common in our pratice and pose a reconstructive challenge ${ }^{14}$.
Reconstruction of large segment of mandible using free rib gave a better functional and cosmetic outcome than if nothing had been done after tumour resection.

Until the technical deficiencies and cost factors ${ }^{15}$ that prevent the adoption of state-of-the-art practices in tissue reconstruction in developing countries are addressed, non-vascularised rib grafts may continue to be used in restoring function and giving a more satisfactory appearance in patients with maxillofacial defects.

\section{CONCLUSION}

In the absence of facilities for vascularised tissue transfer free autogenous rib was used to reconstruct defects in the maxillofacial region with reasonably good results. The survival of the graft was attributed to the stabilization of the graft using intermaxillary fixation; the systemic administration of clindamycin peri-operatively; and the temporary storage of the graft in clindamycin/saline solution prior to implantation.

\section{ACKNOWLEDGEMENT}

We acknowledge the following nursing personnel; Vida Rose Frimpong, Lucy Amoateng, Felicia Sarpong, Victoria Narh, and the nurse anaesthetists, for their assistance with the operations

\section{REFERENCES}

1. Samman N, Cheung LK, Tideman H. Surgical reconstruction of the jaws after ablative surgery. HKMJ 1996; 2: 161-166.

2. Gurtner GC, Evans GR. Advances in head and neck reconstruction. Plast Reconstr Surg 2000; 106: 672-682.

3. Koch WM, Yoo GH, Goodstein ML et al. Advantages of mandibular reconstruction with the Titanium Hollow Screw Osseo-integrating Reconstruction Plate (THORP). Laryngoscope 1994; 104: 545-552.

4. Urken MI, Buchbinder D. Oromandibular reconstruction. In Cummings $\mathrm{C}$ ed. Otolaryngology -Head and neck surgery, $3^{\text {rd }}$ ed. St Louis: Mosby Year Book Inc. 1998; 16541668.

5. Genden E, Haughey BH. Mandibular reconstruction by vascularised tissue transfer. Am J Otolaryngol 1996; 17: 219-227. 
6. Mehta R, Deschler DG. Mandibular reconstruction in 2004: An analysis of different techiques. Curr Opin Otolaryngol Head Neck Surg 2004; 12: 288-293.

7. Hildago DA, Pusic AL. Free flap mandibular reconstruction: A 10-year follow-up study. Plast Reconstr Surg 2002; 110: 438-449.

8. Head C, Alam D, Sercarz JA et al. Microvascular flap reconstruction of the mandible: a comparison of bone grafts and bone bridging plates for restoration of mandibular continuity. Otolaryngol Head Neck Surg 2003; 129: 4854.

9. Lawson W, Biller HF. Reconstruction of the mandible. In: McCarthy JG, ed. Plastic Surgery. $2^{\text {nd }}$ ed. Philadelphia: WB Saunders Co. 1990; 2069.

10. Egyedi P. Wound infection after mandibular reconstruction with autogenous bone grafts. Ann Acad Med Singapore 1986; 15: 340-345.

11. Brook I, Lewis MA, Sanden GK, Jeffcoat M, Samaranayake LP, Rojas J. Clindamycin in dentistry: more than just effective prophylaxis for endocarditis? Oral Surg Oral Med Oral Path Oral Radiol Endod 2005; 100: 550-558.

12. Urken ML, Weinberg $\mathrm{H}$, Vickery $\mathrm{C}$, Buchbinder D, Lawson W, Biller HF. Oromandibular reconstruction using microvascular composite free flaps. Arch Otolaryngol Head Neck Surg 1991; 117: 733-744.

13. Foster RD, Anthony JP, Sharma A, Pogrel MA. Vascularized bone flaps versus nonvascularized bone grafts for mandibular reconstruction: An outcome analysis of primary bony union and endosseous implant success. Head Neck 1999; 21: 66-71.

14. Fonseca RJ, Ed. Reconstruction of the maxillofacial cancer patient. In: Quereshy FA, Powers MP, eds. Oral and maxillofacial Surgery. Philadelphia, Pa: WB Saunders 2000; 361.

15. Kroll SS, Schusterman MA, Reece GP. Costs and complications in mandibular reconstruction. Ann Plast Surg 1992; 29: 341-347. 